\title{
Algumas estratégias de resolução de problemas de divisão
}

\section{Rosemeire Roberta de Lima}

Mestre, UFAL

rose.ufal@yahoo.com.br

\author{
Mercedes Carvalho \\ Professora, UFAL \\ mbettacs@uol.com.br
}

\begin{abstract}
Resumo
O presente artigo trata de uma pesquisa qualitativa, na modalidade de um estudo de caso, acerca das estratégias de resolução de problemas de divisão - partição e quotição - utilizadas por alunos do $4^{\circ}$ ano do Ensino Fundamental. Para a análise das respostas foram criadas duas categorias: aplicação de estratégia e aplicação do algoritmo. Os resultados revelaram que os participantes resolveram as situações-problema pautando-se em seus conhecimentos acerca do campo aditivo com indicações de que utilizam o algoritmo das operações aritméticas de forma mecânica, o que não favorece a construção dos conceitos matemáticos.
\end{abstract}

Palavras-chave: Divisão. Estratégias de Solução de Problema. Resolução de Problemas. Aritmética. Anos Iniciais do Ensino Fundamental.

\section{Some strategies of solving division problems}

\begin{abstract}
This article discusses a qualitative research, in the case study format, it is about the strategies of problem-solving for division - quotição and partition - which are used by students of the 4th year of elementary schools. These students have solved four problem-situations and two categories were created to the analysis of their answers: application of strategy and application of algorithm. The results showed that the participants have resolved the problem-situations, focusing on their knowledge of the additive field with indications that they used the algorithm of arithmetic operations in a mechanical way, what does not favour the construction of mathematical concepts.
\end{abstract}

Keywords: Division. Problem-solving strategies. Problem solving. Arithmetic. Early years of elementary school. 


\section{Introdução}

Investigações em educação matemática que se debruçam sobre os anos iniciais, como a de Carvalho (2007, 2010), indicam que os conteúdos de multiplicação e divisão são considerados pelos professores os mais complexos de serem trabalhados com os alunos. Geralmente os docentes ancoram o trabalho da multiplicação no ensino da tabuada pois, equivocadamente, a maioria deles acredita que se o aluno aprender a tabuada saberá a multiplicação e, consequentemente, a divisão.

Tal crença, acerca do trabalho da multiplicação e divisão, leva-nos a conjecturar que esses conceitos são reduzidos aos procedimentos dos algoritmos dessas operações, o que resulta no empobrecimento do trabalho matemático porque

reduz a matemática a cálculo ou execução de algoritmos, ignorando que a matemática fornece modelos para a representação e compreensão do mundo que vivemos. Em segundo lugar [...] porque o algoritmo se refere a um conjunto de procedimentos que leva à execução de uma dada operação, enquanto a operação implica transformações realizadas sobre números, quantidades, grandezas e medidas (CORREA e SPINILLO, 2004, p. 105).

A investigação realizada por Lima (2012), em que apresentamos um recorte neste artigo, focalizou a divisão, isto porque, de acordo com a experiência da pesquisadora, esse conteúdo é desenvolvido nos anos iniciais somente depois do trabalho com os conteúdos de adição, subtração, multiplicação, o que indica a linearização do currículo caracterizado pelo trabalho pedagógico do mais simples para o mais complexo, limitando, dessa forma, o processo da construção e da compreensão dos conceitos matemáticos pelos alunos e, também, não lhes possibilitando lançar mão dos seus conhecimentos implícitos sobre a divisão para resolverem situações-problema que lhes são apresentadas.

\section{Conceito de divisão}

Teles (2007) conceitua divisão ${ }^{1}$, na perspectiva euclidiana, como uma ação que requer dividir um número por outro em partes iguais, de forma que o resto seja menor que o divisor ou zero. No conjunto dos números naturais o resto na divisão é classificado como resto não nulo ou divisão com resto zero. Nessa direção, Teles (ibid.) argumenta sobre o uso da linguagem equivocada utilizado no cotidiano escolar, em que os professores classificam a divisão como exata, não considerando o zero como resto.

\section{1. $D=a . q+r$}


A operação de divisão envolve duas ideias distintas: a de partição (ação de partilha) e o de quotição (ação de medida). Nos problemas com a ideia de partição o modelo "divida x em y em partes iguais", temos informações sobre "o número total de elementos em um conjunto, que deverá ser distribuído igualmente em um número de partes predeterminados, devendo-se calcular o número de elementos em cada parte" (CORREA, 2006, p. 97). Quanto à ideia de quotição, o modelo "quantos y há em x" nos fornece a informação sobre "o conjunto conhecido deve ser dividido em partes de grandeza previamente estabelecida, devendo-se calcular o número de partes que serão obtidas" (CORREA, 2006, p. 97).

De acordo com Spinillo e Lautert (2006), o aluno compreende, inicialmente, a divisão a partir de um modelo intuitivo que corresponde à noção de repartir (compartilhar) e que, por sua vez, é amplamente trabalhada na sala de aula. No entanto, as referidas autoras observam que a ação de compartilhar/distribuir, própria da correspondência um-a-um, não garante a compreensão do conceito de divisão, pois dividir não é sinônimo da ação de compartilhar, isto é, a ação de dividir socialmente não equivale a dividir em Matemática.

A divisão, em algumas situações de aprendizagem, pode ser apresentada aos alunos como ações de dividir, medir ou cortar determinadas quantidades, mas há diferenças significativas entre elas, porque "dividem-se números e medem-se quantidades" (CARRAHER, 1998, p. 77), ou seja, a divisão está relacionada aos números, enquanto a medida está relacionada a magnitudes físicas. Ainda, dividir não é o mesmo que cortar, pois dividir está relacionado aos conceitos de correspondência de um-para-muitos, enquanto cortar significa a retirada de uma parte, enfim, ideia de redução do todo e não de distribuição por igual, como defendido na divisão euclidiana.

\section{Resolução de Problemas matemáticos acerca de divisão}

Propiciar aos alunos problemas matemáticos desde os anos iniciais caracteriza uma excelente oportunidade para eles criarem diferentes estratégias de resolução, contribuindo com isso para a aprendizagem acerca dos conteúdos matemáticos. Tais práticas no ensino da Matemática possibilita ao professor caminhos de conversar com os alunos a respeito das estratégias e, assim, fazer as intervenções pertinentes, pois nem sempre os alunos têm uma solução pronta, o que os favorecem resolver uma situação para a qual não se dispõe de um caminho rápido de chegar a solução, obtida conforme o seu nível de conceituação, que requer compreensão do assunto, como apresemta Pozo (1998).

Para o referido autor (op. cit), a análise das diferentes estratégias de solução proporciona a distinção entre exercício e problemas. Com isso, Pozo (1988, p. 10) 
destaca que a "solução de problemas matemáticos requer dos alunos diversos tipos de conhecimento, cujo ensino exige que os professores não somente disponham de atividades adequadas, mas sim, o que é mais difícil, concebam o trabalho docente especialmente como uma tarefa de ajuda pedagógica".

Nessa direção, vale destacar que "o termo problema pode fazer referência a situações muito diferentes, em função do contexto no qual ocorrem e das características e expectativas das pessoas que nelas se encontram envolvidas" (POZO, 1998, p. 13). Assim, para ele

uma situação somente pode ser concebida um problema na medida em que exista um reconhecimento dela como tal, e na medida em que não dispomos de procedimentos automáticos que nos permitam solucioná-la de forma mais ou menos imediata, sem exigir, de alguma forma, um processo de reflexão ou uma tomada de decisões sobre a consequência de passos a serem seguidos (POZO, 1998, p. 16).

Isso significa que há distinção entre problema e exercício. Neste, dispomos e utilizamos mecanismos que nos levam, de forma imediata, à solução. Enquanto que no problema faz-se necessário desafio, a vivência de uma situação nova, isto é, a solução não é encontrada por meio de um caminho rápido e direto, mas por meio de ações que exigem a explicitação de estratégias, conhecimentos conceituais, atitudes, como defende Pozo (1998).

\section{Método}

Optamos pela pesquisa qualitativa na modalidade de um estudo de caso que tem por premissa investigar acerca de uma realidade que caracteriza unidade específica, de forma profunda e completa e que tem dinâmica própria por sua contextualidade e especificidade, conforme apontam Fiorentini e Lorenzato (2009). Nesta investigação tratamos das estratégias de resolução de problemas que envolvem a divisão, utilizadas por alunos de três escolas públicas das redes estadual e municipal situadas na cidade de Maceió, escolhidas a partir dos seguintes critérios: ter mais de uma turma de $4^{\circ}$ ano do EF e professores efetivos nas turmas investigadas.

Participaram da investigação 105 alunos, na faixa etária de 8 a 13 anos, das três escolas que integraram a pesquisa. Dentre os participantes há predominância do sexo masculino nas escolas B e C. 


\section{Quadro 1 - Participantes da investigação quanto à solução do instrumento utilizado na pesquisa}

\begin{tabular}{|c|c|c|c|c|c|}
\hline Escolas & $\begin{array}{c}\mathbf{N}^{\mathbf{0}} \text { de } \\
\text { Participantes }\end{array}$ & $\begin{array}{c}\text { Sexo } \\
\text { Feminino }\end{array}$ & $\mathbf{\%}$ & $\begin{array}{c}\text { Sexo } \\
\text { Masculino }\end{array}$ & $\%$ \\
\hline A & 25 & 14 & 56 & 11 & 44 \\
\hline B1 & 17 & 4 & 25,53 & 13 & 74,47 \\
\hline B2 & 27 & 13 & 48,15 & 14 & 51,85 \\
\hline C & 36 & 15 & 41,67 & 21 & 58,33 \\
\hline Total & 105 & 47 & 44,76 & 58 & 55,24 \\
\hline
\end{tabular}

Fonte: Dados coletados nas escolas participantes da pesquisa.

Utilizamos uma atividade com quatro problemas que envolvem situações de divisão - partitiva e quotitiva - e que tratavam de divisão de resto zero.

\section{Quadro 2-Problemas aplicados às turmas do $4^{\circ}$ ano do Ensino Fundamental}

\begin{tabular}{|c|l|l|}
\hline Problema & Situação & Enunciado \\
\hline 1 & Quotição & $\begin{array}{l}\text { Maria fez 30 brigadeiros e irá colocar 5 em cada } \\
\text { saquinho. De quantos saquinhos ela irá precisar? Explique } \\
\text { como chegou à resposta. }\end{array}$ \\
\hline 2 & Partição & $\begin{array}{l}\text { Se repartirmos } 24 \text { pães para } 6 \text { crianças, quantos pães } \\
\text { receberá cada uma? Explique como você chegou à } \\
\text { resposta. }\end{array}$ \\
\hline 3 & Quotição & $\begin{array}{l}\text { Quantas cédulas de 5 reais há em 50 reais? Explique } \\
\text { como você chegou à resposta. }\end{array}$ \\
\hline 4 & Quotição & $\begin{array}{l}\text { Carlos vai fazer aniversário. Cada amigo que vier a } \\
\text { sua festa vai ganhar 3 balões. Ele comprou 18 balões. } \\
\text { Quantos amigos ele pode convidar? Explique como você } \\
\text { chegou à resposta. }\end{array}$ \\
\hline
\end{tabular}

Fonte: Problemas extraídos e adaptados do livro Números, de Carvalho (2010), do livro Introdução à Educação Matemática, de Nunes et al. (2002), e de Zunino (1995), do livro A Matemática na escola: aqui e agora.

A atividade foi aplicada pela professora regente da turma no final do segundo semestre de 2010 e no início de fevereiro de 2011. Os alunos resolveram individualmente durante uma aula com tempo médio de aproximadamente $1 \mathrm{~h} 30$. 


\section{Procedimento para Análise dos Dados}

Para a análise dos dados classificamos as estratégias dos alunos "em categorias de menor amplitude e, em seguida, sem nos afastar dos significados e dos sentidos atribuídos pelos sujeitos da pesquisa, criamos marcos interpretativos mais amplos para reagrupá-los" (FRANCO, 2008, p. 63). Na primeira etapa da análise dos dados analisamos as atividades considerando as práticas de correção utilizadas pelas professoras, principalmente no ensino da Matemática, a fim de tabularmos as respostas dos sujeitos, e para tanto classificamos as soluções em:

1-CERTO - o problema que foi corretamente resolvido utilizando a operação aritmética da divisão ou por meio de representações pessoais (uso de bolas, traços, esquema ou outro desenho que se aproxime da situação do enunciado ou pelo cálculo mental);

2-ERRADO - o problema foi resolvido incorretamente, podendo ser por meio da operação ou resultado do cálculo ou, ainda, por meio de ilustração da situação enfrentada, muito presente nas estratégias das crianças para se chegar a uma solução ou até mesmo para validar suas respostas, porém a estratégia utilizada apresentou registro incoerente com o problema proposto; e

3-em BRANCO - quando os alunos ou não tentaram a solução do problema ou apenas apresentaram a estrutura da operação aritmética.

A partir dessa tabulação passamos para a segunda etapa da análise dos dados elencando as questões corretas para observarmos quais estratégias de resolução predominaram nos problemas.

Para a análise qualitativa, elencamos as principais estratégias utilizadas pelos alunos e as classificamos em sete categorias; 1-algoritmo da adição, 2-algoritmo da multiplicação, 3-algoritmo da divisão, 4-estratégia pessoal (repetição aditiva, repetição subtrativa, fazer um desenho ou uma simulação), 5-estratégias combinadas (algoritmo e ilustração ou algoritmo e linguagem natural), 6-linguagem natural e 7-ensaio e erro.

Para buscar entender o que o aluno compreende acerca do conceito de divisão foi solicitado, em cada um dos problemas, que ele explicasse, por escrito, como chegou à resposta. 


\section{Resultados}

Os alunos que participaram desse estudo, mesmo que ainda não tivessem estudado formalmente o conteúdo divisão, ao responderem à atividade apresentaram diferentes estratégias de resolução, convencionais ${ }^{2}$ e não convencionais ${ }^{3}$ : algoritmo representado na horizontal, na divisão reduzida ou longa, estratégias semelhantes à multiplicação, subtração e adição, desenhos, esquemas. Observamos, também, que poucos alunos justificaram suas estratégias -"como chegou à resposta"-, o que nos levou a conjecturar que pode não ser uma prática usual nas aulas de Matemática. Porém, socializar as soluções encontradas pelos alunos possibilitam aos professores “analisar como o aluno está elaborando o raciocínio para resolver o problema e, os colegas, estabelecer comparações entre a sua maneira de resolver problemas e a do colega" (CARVALHO, 2007, p. 66).

Quanto aos problemas que os alunos resolveram utilizando desenhos e esquemas, percebemos diferenças significativas entre as estratégias utilizadas para responderem à atividade de pesquisa e as atividades presentes em seus cadernos ${ }^{4}$, ou seja, os problemas são resolvidos a partir da aplicação do algoritmo.

Consideramos significativo que apenas $4 \%$ dos alunos que participaram dessa pesquisa tenham deixado de responder às questões, isto porque, de acordo com o plano de trabalho do professor, o conteúdo divisão seria desenvolvido, formalmente, no final do segundo semestre; portanto, eles podem ter utilizado seus conhecimentos implícitos para resolver os problemas propostos ou, também, pode ser que os alunos entendam que todo problema matemático deve ter uma resposta.

\section{Analisando as estratégias}

Devido ao espaço reservado para esse texto, selecionamos apenas cinco categorias significativas das estratégias detectadas em dois problemas, dos quais foram aplicados as turmas participantes da pesquisa, que envolvem um problema de partição (ideia de distribuição/ partição) e um problema de quotição (ideias de correspondência um-para-muitos e medida), para que o leitor tenha uma visão global da pesquisa.

2. Entendidas aqui como soluções realizadas por meio das operações fundamentais da Aritmética em que há um único procedimento de solução.

3. As estratégias não convencionais estão relacionadas a outras formas de solução que não sejam as operações elementares (adição, subtração, multiplicação e divisão), podendo ser via desenho, esquema, tabela etc.

4. Por questão de espaço não tratamos neste artigo acerca da análise do material escolar dos alunos; detemo-nos apenas na análise da atividade elaborada pela pesquisadora. 
Problema 2 - Se repartirmos 24 pães para 6 crianças, quantos pães receberá cada uma? Explique como você chegou à resposta.

\section{a) Algoritmo da divisão}

Ilustração 1 - Estratégia do algoritmo da divisão

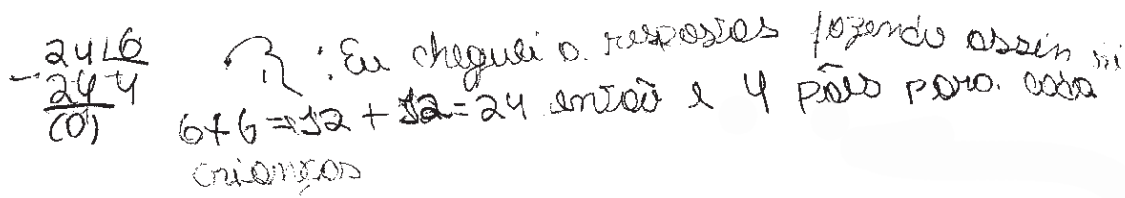

Fonte: Sa6

De acordo com a análise da resposta de Sa6 podemos entender que esse aluno interpretou o problema como sendo de divisão, pois deu sentido aos dados numéricos do enunciado e utilizou, corretamente, o algoritmo da referida operação. Há indicações, também, de que ele, intuitivamente, diferenciou as ideias de partição e quotição, pois como os dados do enunciado não apresentam a mesma grandeza "24 pães" e "6 crianças", a solução se dá na relação das grandezas pães/criança, e parece-nos que esta foi compreendida por esse sujeito, porque ele registrou "4 pães para cada criança". Entretanto, notamos que a sua justificativa ancorou-se em seus conhecimentos acerca da adição, dobro, contagem dos grupos formados. Nessa direção, podemos dizer que para resolver problemas matemáticos, "as técnicas 'sobreaprendidas' previamente exercitadas constituem um meio ou recurso instrumental necessário, mas não suficiente, para alcançar a solução" (ECHEVERRÍA, 1998, p. 17).

\section{b) Estratégias combinadas}

Ilustração 2 - Estratégias combinadas (repetição aditiva - algoritmo da adição e algoritmo da divisão).

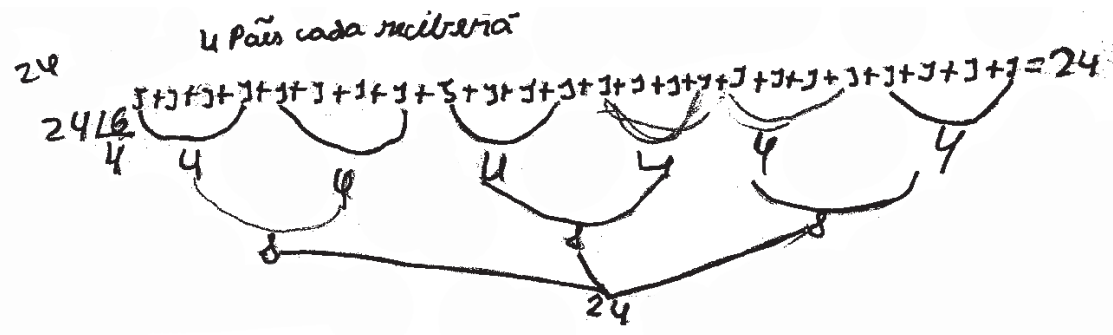

Fonte: Sc11 
O sujeito Sc11 demonstrou ter realizado a interpretação do enunciado. Entretanto, a análise da sua estratégia nos possibilitou depreender que, possivelmente, ele tenha noções do algoritmo da divisão, porém, pode ser que ainda não saiba usá-lo, isso porque, além de não ter registrado o resto zero e o quociente 6 no algoritmo para resolver o problema, há indícios de que ele tenha calculado o quociente mentalmente e para justificar a sua resposta, decompôs o todo (24 pães) em unidades $(1+1+1 \ldots 1)$; em seguida, agrupou de $4 \mathrm{em} 4$, caracterizando a distribuição dos 24 pães para 6 crianças em partes iguais e certificou-se da sua contagem somando de 4 em 4, de 8 em 8.

Nessa direção, podemos inferir que Sc11 se viu diante de um problema e não de uma simples atividade porque, segundo Pozo (1998), quando o aluno compreende o enunciado e tem vivência da situação enfrentada, a solução, geralmente, ocorre por meio de um caminho mais curto, neste caso a aplicação do algoritmo. Tal resolução indica que Sc11 ainda utiliza os seus conhecimentos do campo aditivo.

\section{c) Algoritmo da multiplicação}

Problema 3 - Quantas cédulas de 5 reais há em 50 reais? Explique como você chegou à resposta.

Ilustração 3 - Solução do problema 3 por meio da técnica da multiplicação
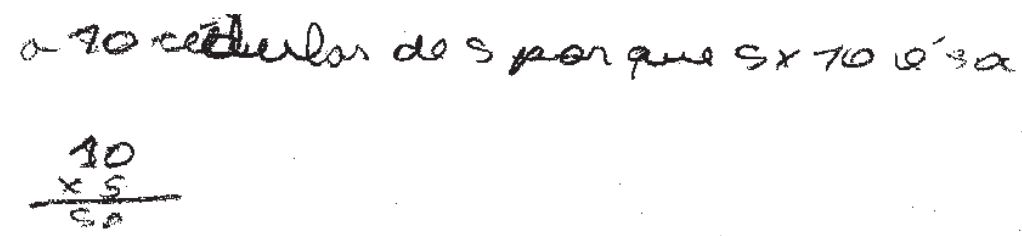

Fonte: $\operatorname{Sc} 30$

O Sc30 resolveu o problema de divisão por meio da operação da multiplicação. Sua justificativa " 10 cédulas de 5 porque 5 x 10 é 50 " nos permite concluir que ele utilizou seus conhecimentos acerca da tabuada do 5. É interessante notar que ele explica a sua resposta com a propriedade comutativa da multiplicação, pois escreve 10 cédulas de 5 (monta o algoritmo 10 x 5) e justifica escrevendo "porque 5 x 10", ou seja, de maneira implícita ele demonstra entender que a ordem dos fatores não altera o produto.

Como o problema apresentado envolve valores monetários, a situação pode parecer mais próxima ao cotidiano desse aluno, o que pode lhe ter favorecido a 
solução do problema. Porém, entendemos que, mesmo que esse aluno Sc30 tenha resolvido o problema e que a multiplicação e a divisão fazem parte do campo multiplicativo, por estar cursando o $4^{\circ}$ ano do ensino fundamental, ele poderia ter utilizado a divisão $50 \div 5$ para resolver a situação proposta.

\section{d) Estratégia pessoal}

Problema 3 - Quantas cédulas de 5 reais há em 50 reais? Explique como você chegou à resposta.

Ilustração 4 - Solução do problema 3 por meio da representação do enunciado
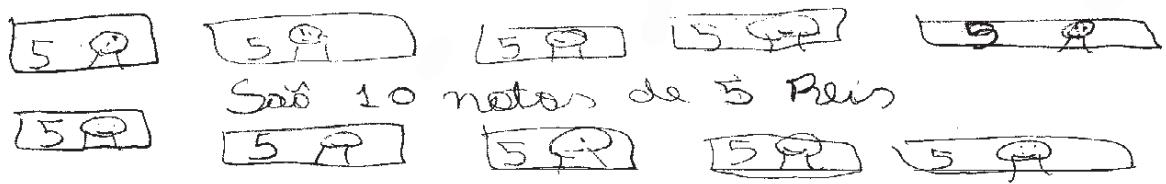

Fonte: $\mathrm{Sa} 2$

Nesta solução, Sa2 apresenta indícios de que tomou como base a contagem das quantidades de notas de 5 reais para obter o valor de 50 reais. Na resposta "são 10 notas de 5 reais" demonstra ter feito o cálculo mental, tendo em vista que não há registro do algoritmo.

Acreditamos que o reconhecimento do sistema monetário, bem como a mobilização dos seus conhecimentos o favoreceu na solução do problema. Entretanto, conjecturamos que o referido aluno não relacionou os dados numéricos do problema com a operação da divisão, pois resolveu por meio da decomposição dos 50 reais e da contagem de 5 em 5 reais. Tal procedimento corrobora a pesquisa de Spinillo e Lautert (2006), quando afirmam que os alunos, mesmo que ainda não tenham sido formalmente ensinados, conseguem, à sua maneira, resolver problemas escolares ou do cotidiano.

No entanto, a solução desse aluno seria adequada para um aluno do último estágio da educação infantil ou do $1 \% 2^{\circ}$ ano do ensino fundamental, pois o problema traz elementos simples e números pequenos, ou seja, prevaleceu, possivelmente, uma solução mediada pelo seu conhecimento social e não pelo seu conhecimento matemático, no que se refere ao conceito de divisão com a ideia de quotição, que requer, conforme Nunes et al. (2002), a identificação do invariante conceitual, caracterizado pela existência de uma relação fixa entre duas variáveis. 


\section{e) Língua materna}

Problema 3 - Quantas cédulas de 5 reais há em 50 reais? Explique como você chegou à resposta.

Ilustração 5 - Solução do problema 3 por meio da escrita convencional, a linguagem natural.

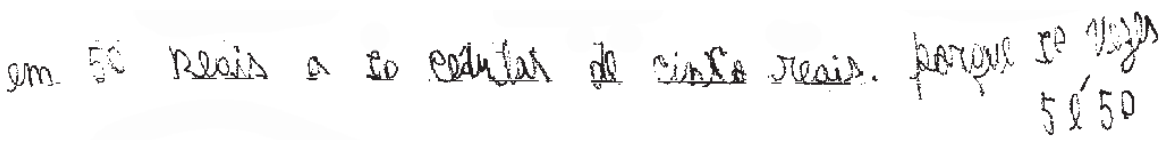
Fonte: Sa15

O Sa15 apresentou uma solução pautada no campo multiplicativo, uma vez que em linguagem natural sinalizou que reconheceu os dados do enunciado, optando pela inversão da divisão, pois, conforme Caraça (1984, p. 22), "dado o dividendo e o divisor, se determina um terceiro número, quociente, que multiplicado pelo divisor dá o dividendo".

A solução desse aluno demonstrou que ele identificou as grandezas presentes na situação: a quantidade e a quantia de cédulas são familiares. Nesse sentido, parece-nos que o aluno estabeleceu relações entre a Matemática da escola e a Matemática da vida, pois atribuiu sentido à situação enfrentada. Além disso, o aluno revela ter utilizado o conhecimento da tabuada, quando diz "10 vezes 5 é 50".

Convém ressaltar que Nunes et al. (2002, p. 91) consideram os problemas de divisão de quotas como problemas inversos da multiplicação porque "os alunos resolvem o problema com a mesma estratégia que utilizam para resolver problemas de multiplicação". Perceber essa relação faculta ao aluno pensar em procedimento que se utiliza da correspondência e não da distribuição.

Verificamos ainda, na solução desse problema, que o aluno não tratou a escrita dos valores das cédulas de forma diferente dos números naturais ou inteiros positivos. Podemos conjecturar que o enunciado influenciou para o registro das cédulas na forma de números inteiros e que a escrita de números decimais ou racionais ainda não lhe é familiar em ambiente escolar, no que se refere à forma de registro do nosso sistema monetário, o real.

Inferimos que o conteúdo estudado ${ }^{5}$ não lhe deu possibilidades de estabelecer relações entre os números decimais e a escrita convencional do nosso sistema

5. Tendo em vista que a atividade foi aplicada em turmas do $4^{\circ}$ ano do Ensino Fundamental, vale ressaltar que as turmas envolvidas ainda estavam estudando multiplicação, em virtude de práticas lineares no Ensino da Matemática constatadas nos cadernos dos alunos envolvidos. 
monetário. Tais indícios comprovam que o ensino de Matemática foi apresentado a esse aluno de forma estanque/fragmentada, não havendo a utilização do espaço da sala de aula para discussões, comparações, identificação de semelhanças, diferenças, como é proposto na metodologia de resolução de problemas.

Logo, embora a multiplicação seja parte do campo multiplicativo, a solução do aluno não atendeu ao raciocínio requerido na situação proposta, pois o raciocínio a ser realizado em problema de quotição requer a descoberta do número de grupos a serem formados, e não do número de elementos do grupo. Na resposta do aluno, a incógnita já foi evidenciada na solução. Neste sentido, o procedimento utilizado foi incoerente com o problema proposto.

\section{Considerações Finais}

Neste artigo apresentamos as cinco estratégias (algoritmo da divisão, estratégias combinadas, algoritmos da multiplicação, estratégia pessoal e língua materna) de solução oriundos de dois problemas que envolvem as ideias de divisão partitiva e quotitiva solucionados por cinco alunos do $4^{\circ}$ ano do Ensino Fundamental, selecionados aleatoriamente. Suas respostas indicam a necessidade de pautar o ensino da Matemática por meio da resolução de problemas, pois a referida proposta de trabalho possibilita promover atividades que resultam no desenvolvimento do pensamento matemático dos alunos.

As estratégias desses alunos nos possibilitam conjecturar que, nas suas aulas de Matemática houve linearização do conteúdo aritmético e o ensino da multiplicação foi ancorado na aprendizagem mecânica da tabuada ou, apenas, como a forma simplificada da adição. Há indicações, também, que esses alunos se envolvem com as atividades que lhes são propostas pois, mesmo não tendo estudado o conteúdo proposto, eles mobilizaram seus conhecimentos, resolveram os problemas e procuraram justificar as suas estratégias, mesmo que, possivelmente, durante as aulas de Matemática não seja habitual falar sobre a Matemática; um momento privilegiado, isso porque, ao verbalizarem seu raciocínio "o professor tem a possibilidade de compreender como o seu aluno está construindo conhecimento e a partir daí fazer as intervenções" (CARVALHO, 2010, p.20) e o aluno entender que para um mesmo problema existem diferentes estratégias, mas que algumas podem ser mais simples do que outras.

Entretanto, mesmo com os dados positivos ora relatados, consideramos que por esta pesquisa ter sido realizada com alunos de um $4^{\circ}$ ano do Ensino Fundamental, as estratégias apresentadas por eles seriam mais adequadas se estivessem cursando o $1^{\circ}$ ou o $2^{\circ}$ ano do Ensino Fundamental, porque nestes anos se inicia o 
processo da alfabetização matemática. É desejável que alunos do $4^{\circ}$ ano do Ensino Fundamental já entendam e trabalhem com as operações aritméticas e tenham bom desenvolvimento de leitura e escrita.

\section{Referências}

CARAÇA, B. de J.. Conceitos Fundamentais da Matemática. Lisboa: Livraria Sá da Costa Editora, 1984.

CARRAHER, D. W. Relações entre razão, divisão e medida. In: SCHLIEMANN, Analúcia; CARRAHER, D. W. (org.). A compreensão de conceitos aritméticos: ensino e pesquisa. São Paulo: Papirus, 1998, p. 73-94. (Perspectivas em educação matemática).

CARVALHO, M. Problemas? Mas que problemas?!: estratégias de resolução de problemas matemáticos em sala de aula. $3^{\mathrm{a}}$ ed. Petrópolis, RJ: Vozes, 2007.

CARVALHO, M. Números: conceitos e atividades para Educação Infantil e Ensino Fundamental I. Petrópolis, RJ: Vozes, 2010.

CORREA, J.; SPINILLO, A. G. A resolução de tarefas de divisão por crianças. Estudos da Psicologia, Natal, v. 9, nº 1, 2004.

CORREA, J. A compreensão intuitiva da criança acerca do conceito de divisão por cotas de quantidades contínuas. In: BRITO, M. R. F. de (org.). Solução de problemas e a matemática escolar. Campinas: Alínea Editora, 2006, p. 185-206.

ECHEVERRÍA, $M^{\mathrm{a}}$. D. P. et al. Aprender a resolver problemas e resolver problemas para aprender. In: POZO, J. I. (org.). A solução de problemas: aprender a resolver, resolver para aprender. Porto Alegre: ArtMed, 1998, p. 13-42.

FIORENTINI, D.; LORENZATO, S. Investigação em educação matemática: percursos teóricos e metodológicos. Campinas, SP: Autores Associados, 2009.

FRANCO, Ma . L. P. B. Análise do Conteúdo. Brasília: Liber Livro Editora, 2008.

LIMA, R. R. Campo multiplicativo: estratégias de resolução de problemas de divisão de alunos do $4^{\circ}$ ano do Ensino Fundamental em escolas públicas de Maceió. 
Dissertação (Mestrado em Ensino de Ciências e Matemática) - Universidade Federal de Alagoas, Maceió, 2012.

NUNES, T. et al. Introdução à Educação Matemática: os números e as operações numéricas. São Paulo: PROEM, 2002.

POZO, J. I. (org.). A solução de problemas: aprender a resolver, resolver para aprender. Porto Alegre: ArtMed, 1998.

SPINILLO, A. G.; LAUTERT, S. L. O diálogo entre a psicologia do desenvolvimento cognitivo e a educação matemática. In: MEIRA, L. L.; SPINILLO, A. G. Psicologia cognitiva: cultura, desenvolvimento e aprendizagem. Recife: Ed. Universitária da UFPE, 2006, p. 46-79.

TELES, R. A. de M. Imbricações entre os campos conceituais na matemática: um estudo sobre as fórmulas de área de figuras geométricas planas. 2007. Dissertação (Mestrado em Educação) - Universidade Federal de Pernambuco, Recife, 2007.

ZUNINO, D. L. A matemática na escola: aqui e agora. Tradução: Juan Acuña Lhorens. Porto Alegre: ArtMed, 1995.

Submetido em novembro de 2012. Aprovado em fevereiro de 2013. 